\title{
Cutis laxa-Marfanoid syndrome
}

INSERM

\section{Source}

INSERM. (1999). Orphanet: an online rare disease and orphan drug data base. Cutis laxaMarfanoid syndrome. ORPHA:171719

A rare, genetic, developmental defect with connective tissue involvement syndrome characterized by neonatal cutis laxa, marfanoid habitus with arachnodactyly, pulmonary emphysema, cardiac anomalies, and diaphragmatic hernia. Mild contractures of the elbows, hips, and knees, with bilateral hip dislocation may also be associated. There have been no further descriptions in the literature since 1991. 